\title{
Cooling Characteristics of the Twin-Roll Rapid Solidification Process*
}

\author{
By Ken-ichi Miyazawa**, Takao Choh*** and Michio Inouye***†
}

\begin{abstract}
The microscopic solidification structure of a $\mathrm{Pb}-\mathrm{Sb}$ eutectic alloy prepared by the twin-roll rapid solidification process has been examined to understand cooling characteristics of the process. The result shows that the average size and the area ratio of globular structure mainly consisting of $\mathrm{Sb}$ have minima for a certain roll rotation speed and decrease with decreasing initial roll gap. The effect of melt flow rate on the structure has not been detected under the adopted experimental conditions.

Regarding the relationship between the solidification structure and the cooling rate of melt, a preliminary experiment of the rapid quenching from melt has revealed that with increasing cooling rate the structure consisting of $\mathrm{Sb}$ phase becomes globular and the average size decreases.

Furthermore, velocity and temperature fields of the process were estimated using a mathematical model to discuss effects of key process parameters on cooling rates of the rapidly solidified metallic ribbons. The estimated results show that under the adopted experimental conditions the mean cooling rate in the melt region between rolls has a maximum for a certain roll rotation speed and increases with decreasing initial roll gap. These theoretical predictions qualitatively agree with results obtained from the observed solidification structure.
\end{abstract}

(Received May 31, 1983)

Keyzords: rapid solidification, rapidly solidified metallic ribbon, solidification structure, cooling rate, twin-roll process, heat transfer, lead-antimony eutectic alloy

\section{Introduction}

The twin-roll method by which melt is directly rolled to solid ribbon is currently regarded as one of the most useful rapid solidification processes for producing metallic ribbons. Because interests in the rapidly solidified metals are growing these days, it is a pressing need to obtain fundamental data on characteristics of the process. In a previous paper $^{(1)}$, the experiment of the twin-roll process was done using a low melting temperature alloy, and the rolling deformation flow of the metal solidified in the roll gap was theoretically analysed to explore the rolling characteristics and the factors controlling the ribbon geometry.

On the production of rapidly solidified rib-

* This paper was originally published in Japanese in J. Japan Inst. Metals, 46 (1982), 1102.

** Department of Metallurgical Engineering, Faculty of Engineering, Nagoya University, Nagoya 464, Japan. Present address: R. \& D. Laboratories-I, Nippon Steel Corporation, 1618, Ida, Nakahara-ku, Kawasaki 211, Japan.

*** Department of Metallurgical Engineering, Faculty of Engineering, Nagoya University, Nagoya 464, Japan.

***† Now Professor Emeritus of Nagoya University. bons, it is also basically important to understand cooling characteristics of the process which closely relates to the solidification structure of ribbons, in addition to modifying or controlling the process so as to yield better ribbons of uniform dimensions. However, since complicated heat and momentum transfers of melt and solid take place in the roll gap, the dependence of the solidification structure on the cooling conditions or the process variables has not been well known.

Thus, in the present study, the solidification structure of a metallic ribbon produced by the twin-roll process is examined to explore effects of the key process parameters on the cooling rate and on the structure of the ribbon. Furthermore, velocity and temperature fields in the roll gap and the cooling rate of ribbon are estimated using a mathematical model to reveal cooling characteristics of the process.

\section{Method}

\section{Microscopic examination of solidification structure}

Using a $\mathrm{Pb}-\mathrm{Sb}$ eutectic alloy, the experiment 
of the twin-roll process was done by systematically changing the key process parameters, namely the roll rotation speed, the initial roll gap and the melt flow rate. The other experimental conditions are the same as those adopted in the previous study ${ }^{(\mathbf{1})}$. Solidification structure of the ribbon produced was microscopically observed on a cross-section vertical to the length-direction by the use of an etching reagent composed of nitric acid $\left(1.4 \mathrm{kmol} / \mathrm{m}^{3}\right.$, $\left.8 \mathrm{~cm}^{3}\right)$, glacial acetic acid $\left(16 \mathrm{~cm}^{3}\right)$ and glycerin $\left(76 \mathrm{~cm}^{3}\right)^{(2)}$.

Effects of the process parameters on the solidification structure can be explored from the result of the experiment mentioned above. However, in order to examine cooling characteristics of the process on the basis of the experimental result, a relation between the structure and the cooling rate has to be known in advance. Regarding the effect of cooling rate on the solidification structure of $\mathrm{Pb}-\mathrm{Sb}$ alloy, hitherto, Kotler et al. ${ }^{(3)}$ and Spittle and Lloyd ${ }^{(4)}$ have reported that for the hypoeutectic compositions the primary and the secondary dendrite arm spacings decrease with increasing cooling rate and solidification velocity. For the hypereutectic compositions, Bode and Löhberg ${ }^{(5)}$ have observed squarish $\mathrm{Sb}$ crystals of the structure to become globular as the cooling rate increases. However, the observation for the eutectic composition and for a higher cooling rate has not been presented. Thus, a preliminary melt quenching test was done to make the relation between the cooling rate and the structure clear. In the test, the melt which was kept at a given temperature in a quartz or graphite tube closed at one end was fallen into different kinds of cooling media together with the tube. The cooling rate of the melt was measured using a CA thermocouple $(0.1 \mathrm{~mm} \phi)$ and a transient wave memory analyser of thermoelectromotive force.

\section{Estimation of cooling rate by mathematical model}

Mathematical models of the heat transfer occurring in the roll gap $^{(6)(7)}$ have been presented for evaluation of the cooling rate of the metallic ribbons produced by the twin-roll process. These models considering only one-dimensional thermal conduction in the thickness-direction of ribbon are relatively convenient for use, but the flow effects of melt and solidified metal on the cooling rates can not be predicted by the models.

Taking account of the flows, a mathematical model of the twin-roll process ${ }^{(8)}$ has been developed. Using the model, in the present study, the velocity and temperature fields in the roll gap and the cooling rate of the ribbons produced in the experiment have been estimated to examine effects of the process parameters on them. In the estimation, the roll gap enlarged during rolling and the end point of solidification are calculated on the basis of the previous theoretical analysis on the rolling of solidified metal $^{(1)}$, resulting in that both the calculated ribbon thickness and roll separating force agree with the observed values, respectively, while a trial-and-error calculation is necessary to know a location where melt begins to be in contact with roll surfaces. Thermal properties used for the calculation are as follows; the specific heat $c=0.15 \mathrm{~kJ} /(\mathrm{kg} \cdot \mathrm{K})$, the thermal conductivity $k_{l}=16.7 \mathrm{~W} /(\mathrm{K} \cdot \mathrm{m})$ for melt and $k_{\mathrm{s}}=29.3$ for solid, the latent heat of solidification $\lambda=$ $38.5 \mathrm{~kJ} / \mathrm{kg}$, the heat transfer coefficient on roll surface $h=41.8 \mathrm{~kW} /\left(\mathrm{m}^{2} \cdot \mathrm{K}\right)$, the melt temperature in nozzle $T_{0}=553 \mathrm{~K}$, the solidification temperature $T_{\mathrm{s}}=525 \mathrm{~K}$ and the roll surface temperature $T_{\mathrm{r}}=293 \mathrm{~K}$. Further, the metal density $\rho=10.5 \mathrm{Mg} / \mathrm{m}^{3}$ and the stress exponent on the deformation of solidified metal $m=6$ are used.

\section{Results and Discussion}

\section{Relation between solidification structure and cooling rate}

The solidification structure observed in the preliminary quenching test is shown in Fig. 1 with the cooling rate averaged over a period during which the melt temperature is reduced from the initial to the equilibrium solidification temperature $(525 \mathrm{~K})$ on the observed cooling curves. Each micrograph in Fig. 1 shows the structure in a cross-section of the solidified metal bar parallel with the heat flow direction in the middle between the surface and the cen- 


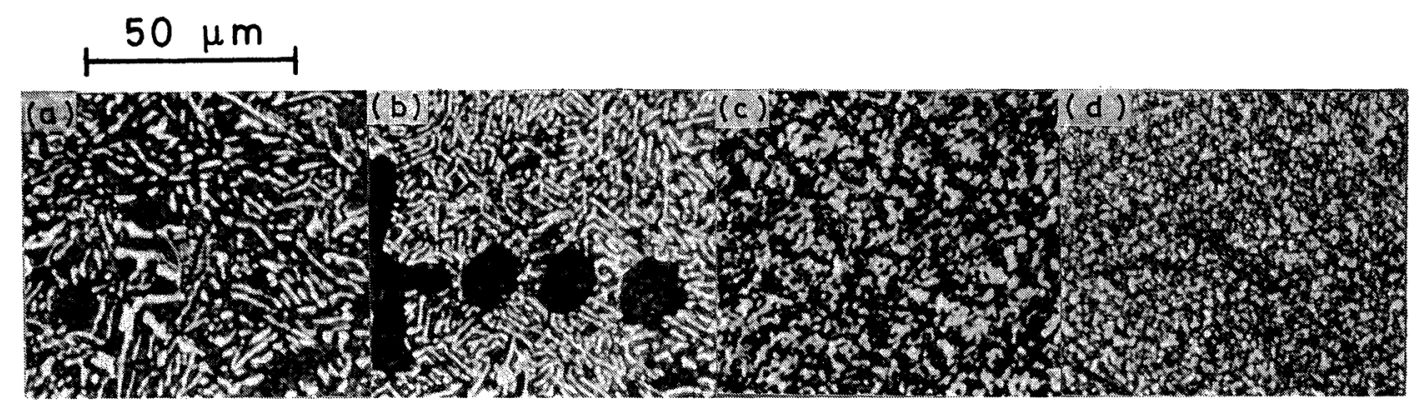

Fig. 1 Change in solidification structure of $\mathrm{Pb}-\mathrm{Sb}$ eutectic alloy with average cooling rate of melt. (Cooling rate) (a): 3.1, (b): 8.9, (c): 290, (d): $2100 \mathrm{~K} / \mathrm{s}$, (Cooling media) (a), (b): air, (c): water, (d): mercury, (Mold) (a)-(c): quartz tube, (d): graphite tube, (Diameter of solidified metal) (a): 2.5 , (b): 1.5 , (c): 2.5 , (d): $2.0 \mathrm{~mm}$.

ter. The diameter of the metal bar was so small that the difference in the structure was not clearly detected over the cross-section. It can be seen from Fig. 1 that with increasing cooling rate a white structure of $\mathrm{Sb}$ changes to globular form and the size decreases. This tendency agrees with that observed by Bode et al. ${ }^{(5)}$ for the hypereutectic composition.

Based on the equilibrium phase diagram for $\mathrm{Pb}-\mathrm{Sb}$ alloy ${ }^{(9)}$, the structure is constituted by $\alpha$ and $\beta$ phases (i.e., solid solutions composed mainly of $\mathrm{Pb}$ and $\mathrm{Sb}$, respectively), when the melt is very slowly cooled to room temperature. Since the volume ratio of the equilibrium $\beta$ phase for the eutectic composition is small (about $17 \mathrm{vol} \%$ ), the structure is usually observed as an anomalous eutectic in which the second phase ( $\beta$ phase) discontinuously distributes in the matrix ( $\alpha$ phase $)^{(10)(11)}$. With increasing cooling rate, the nucleation frequency of $\beta$ phase is increased by the extended undercooling of melt, while the growth of $\beta$ phase is suppressed because of the insufficient diffusion time of solute during the rapid solidification. This results in the refinement of the white $\beta$ phase in Fig. 1.

B-Gautier et al. ${ }^{(12)}$ have rapidly quenched $\mathrm{Pb}-\mathrm{Sb}$ alloys from the melts to examine the structure using X-ray diffraction. Their results show that both the solid solubility of $\mathrm{Sb}$ in $\alpha$ phase and that of $\mathrm{Pb}$ in $\beta$ phase are extended when the cooling rate is high. From the results in Fig. 1 and those obtained by B-Gautier et al., the relation between the solidification structure of the $\mathrm{Pb}-\mathrm{Sb}$ eutectic alloy and the cooling rate can be described as follows; with increasing cooling rate, $\beta$ phase of $\mathrm{Sb}$ becomes globular in form and finer in size and more amount of the melt transforms to the $\alpha$ solid solution in which $\mathrm{Sb}$ is supersaturated.

\section{Effects of process parameters on the solidification structure of ribbon}

Figure 2 shows the solidification structure of the rapidly solidified ribbons obtained in the experiment of the twin-roll process, in which the roll rotation speed was changed. Both the thickness and the width of ribbon decrease with increasing roll rotation speed. The size of the white Sb crystals in Fig. 2 is smaller in average than that in Fig. 1(d). Moreover, the number of the white crystals about $1-3 \mu \mathrm{m}$ in size and the area ratio are smaller than those in Fig. 1(d). Thus, the cooling rate of the ribbons produced by the twin-roll process is presumed to be higher than the case of Fig. 1(d) $\left(2.1 \times 10^{3} \mathrm{~K} / \mathrm{s}\right)$. In Fig. 2, the number and the area ratio of the white $\mathrm{Sb}$ crystals larger than about $1 \mu \mathrm{m}$ decrease with increasing roll rotation speed and has the minimum at $37.5 \mathrm{~s}^{-1}(2250 \mathrm{rpm})$. This indicates that the cooling rate of ribbon has the maximum at the roll rotation speed of $37.5 \mathrm{~s}^{-1}$.

In the twin-roll process, because the metal solidified in the roll gap is subsequently deformed by the rolls, the structure might be affected by the deformation, differing from the case of the static solidification in Fig. 1. With increasing roll rotation speed, the end point of solidification moves downwards in the roll gap, and thus the reduction ratio in thickness of the solidified metal $\left(\left(H_{2}-H_{1}\right) / H_{1}\right)$ decreases, $H_{2}$ being half the thickness at the end point of 


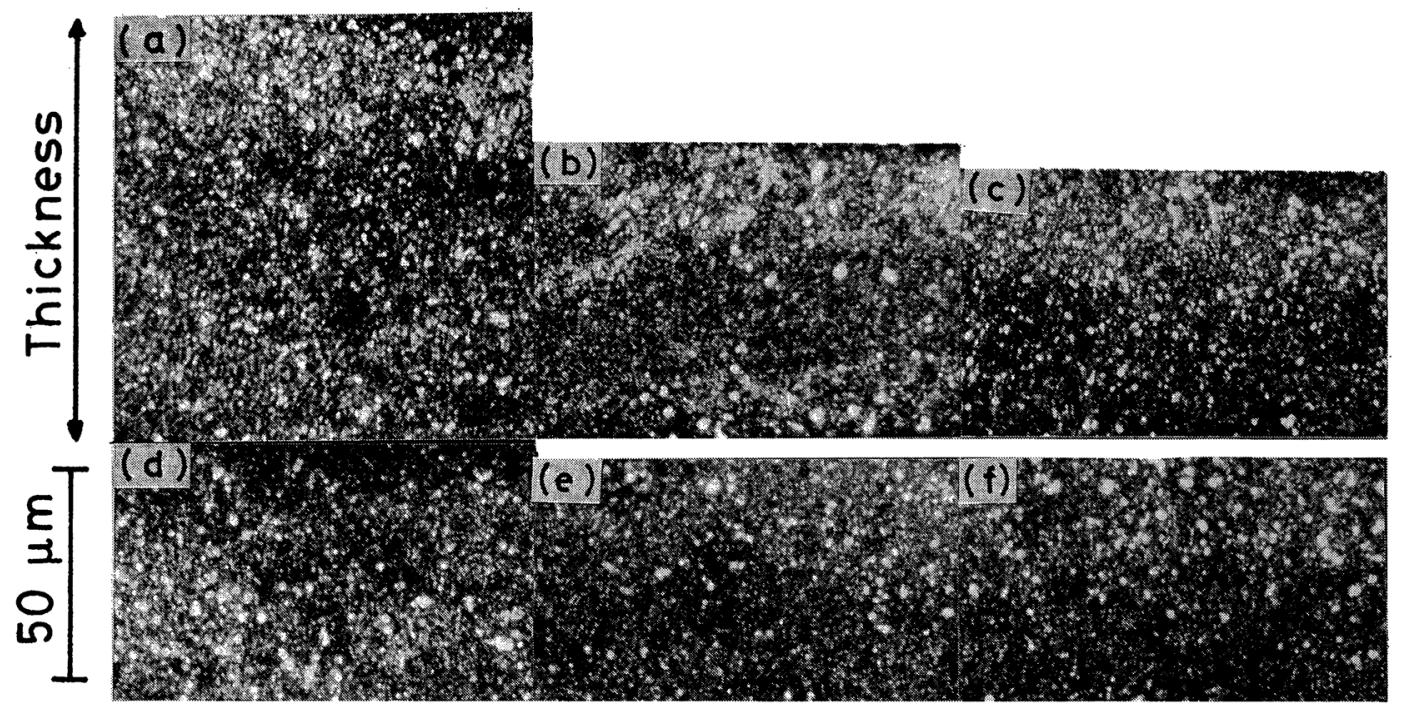

Fig. 2 Effect of roll rotation speed $\left(\omega_{0}\right)$ on solidification structure of rapidly solidified ribbon. ( $\omega_{0}=$ (a) 4.7 (280), (b) 12.5 (750), (c) 20.8 (1250), (d) 29.2 (1750), (e) 37.5 (2250), (f) $45.0 \mathrm{~s}^{-1}$ $(2700 \mathrm{rpm})$, initial roll gap $2 H_{00}=50 \mu \mathrm{m}$, melt flow rate $Q^{\prime}=2.0 \mathrm{~g} / \mathrm{s}$ )

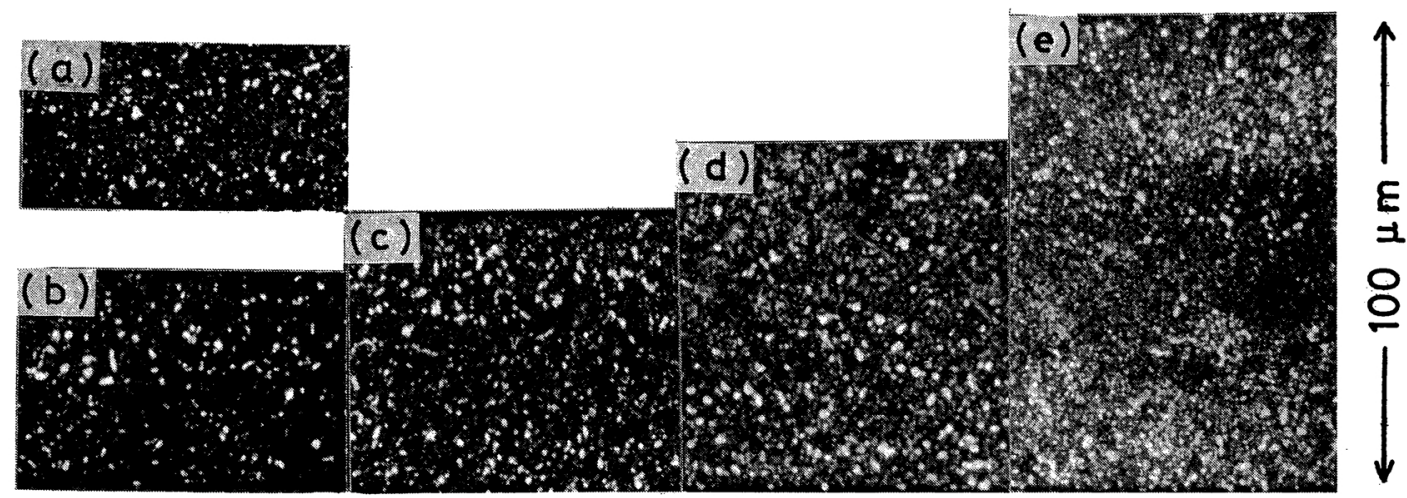

Fig. 3 Effect of initial roll gap $\left(2 \mathrm{H}_{00}\right)$ on solidification structure of rapidly solidified ribbon. $\left(2 H_{00}=\right.$ (a) 0 , (b) 30 , (c) 50 , (d) 70 , (e) $100 \mu \mathrm{m}$, roll rotation speed $\omega_{0}=20.8 \mathrm{~s}^{-1}(1250 \mathrm{rpm})$, melt flow rate $\left.Q^{\prime}=2.7 \mathrm{~g} / \mathrm{s}\right)$

solidification and $H_{1}$ at the outlet. Based on the previous estimation method ${ }^{(1)}$, the reduction ratio for the experimental conditions in Fig. 2 decreases from 0.84 to 0.22 with increasing roll rotation speed from $4.7 \mathrm{~s}^{-1}(280 \mathrm{rpm})$ to $45.0 \mathrm{~s}^{-1}(2700 \mathrm{rpm})$. Thus, the effect of the deformation flow would more easily appear on the structure as the roll rotation speed is lower, although the effect is not remarkably observed in Fig. 2.

Figure 3 shows the effect of initial roll gap on the solidification structure of ribbon. It is seen that the number of the white $\mathrm{Sb}$ crystals larger than about $1 \mu \mathrm{m}$ decreases with decreasing initial roll gap, and the structure entirely becomes finer. Thus, in the light of the qualitative relation between the structure and the cooling rate mentioned in the previous section, it is considered that the cooling rate of ribbon increases with decreasing initial roll gap. The decrease in the initial roll gap makes the ribbon thicker and wider. With it, the end point of solidification moves upwards, and as the result the reduction ratio in metal thickness increases. The estimated reduction ratio is $0.93,0.80$, $0.62,0.46$ and 0.28 , respectively, when the initial 
roll gap is $0,30,50,70$ and $100 \mu \mathrm{m}$. So, the structure would be more easily affected by the rolling deformation, as the initial roll gap is smaller.

In order to examine effects of the melt flow rate on the structure, several experimental runs were conducted under the melt flow rate of $1-4 \mathrm{~g} / \mathrm{s}$ by keeping the roll rotation speed $\left(20.8 \mathrm{~s}^{-1}\right)$ and the initial roll gap $(25$ or $55 \mu \mathrm{m})$ constant. Under these conditions, however, no distinguished effect of the flow rate was detected on the structure.

\section{Effects of process parameters on the cooling rate of ribbon}

Since the deformation flows of melt and solid and the heat transfer to roll surfaces simultaneously take place in the twin-roll process, a coupling of the calculations of velocity and temperature fields is necessary for evaluating the cooling rate of ribbon. However, the coupled calculation is not a so hard task, because an analytical solution for the velocity field is applied in the mathematical model ${ }^{(8)}$ used, though the temperature distribution and the solidification profile are numerically computated by an implicit finite difference method.

The velocity field estimated for the present experimental condition is shown in Fig. 4 using a stream function $(\Psi)$ defined by eq. (1).

$$
\partial \Psi / \partial y=-2 v_{\mathrm{x}} / q, \quad \partial \Psi / \partial x=2 v_{\mathrm{y}} / q
$$

where $v_{\mathrm{x}}$ and $v_{\mathrm{y}}$ denote velocities in casting and thickness directions, respectively, and $q$ a volumetric melt flow rate per unit width. In

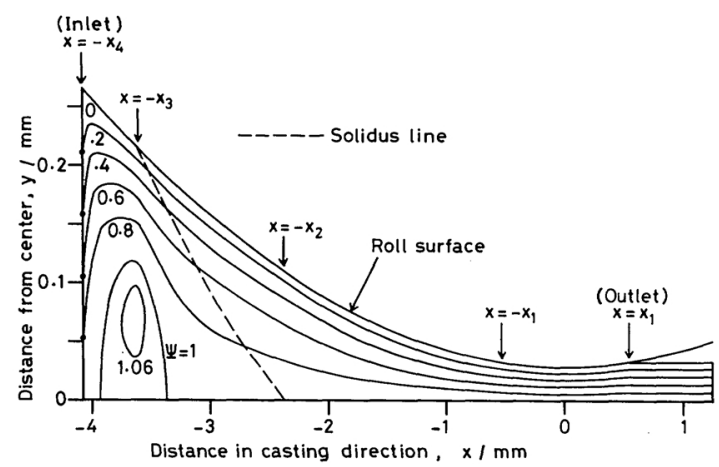

Fig. 4 Flow pattern between rolls estimated for roll rotation speed of $16.7 \mathrm{~s}^{-1}(1000 \mathrm{rpm})$. (Initial roll gap $2 H_{00}=50 \mu \mathrm{m}$, melt flow rate $Q^{\prime}=2.0 \mathrm{~g} / \mathrm{s}$ )
Fig. 4, the melt flowing down from the inlet position to the roll surface solidifies at the solidus front shown by a broken line. A circulating flow is observed in the upper melt region of roll gap, which results from the fact that the distance between rolls gets narrower toward the $x$-direction. After the complete solidification of the melt, the solidified metal is deformed to flow through the roll gap. The velocity in the $x$-direction has the maximum at $x=0$ in Fig. 4 .

Figure 5 shows the flow pattern computed for a higher roll rotation speed. From the comparison between Figs. 4 and 5, it can be seen that both the inlet position and the end point of solidification move downwards as the roll speed is higher and the thickness of metal at these positions becomes thinner. The distance between the inlet and a position where the solidification begins increases with increasing roll rotation speed. This indicates that the temperature gradient in the casting direction is lowered by the increase in roll rotation speed.

Figure 6 shows the change in the crosssectional mean temperature of metal with distance in the casting direction. The temperature decreases from the inlet position, and on the way the change in the temperature slows down due to the release of the latent heat of solidification. After finish of the solidification the temperature again decreases rapidly. It should be noted that the ribbon temperature at the outlet position increases with increasing roll rotation speed.

The result in Fig. 6 suggests that the melt passes through the roll gap without solidifying

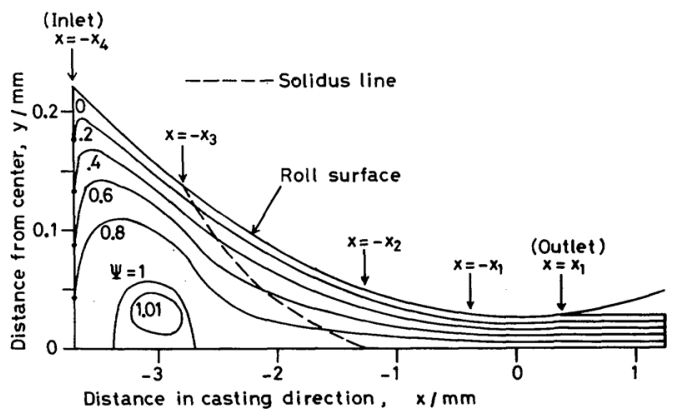

Fig. 5 Flow pattern between rolls estimated for roll rotation speed of $33.3 \mathrm{~s}^{-1}(2000 \mathrm{rpm}) . \quad\left(2 H_{00}=\right.$ $50 \mu \mathrm{m}, Q^{\prime}=2.0 \mathrm{~g} / \mathrm{s}$ ) 
completely, when the roll rotation speed is too high. On the other hand, the decrease in the ribbon temperature at the outlet position with decreasing roll speed causes the roll temperature to increase, because more heat transfers from the metal to the rolls. It follows that cooling ability of the rolls is lowered when the solidified metal is cooled in excess in the roll gap. Thus, an optimum roll rotation speed should be sought by considering the complete solidification of melt in the roll gap and a minimum increase in roll temperature.

When the metal temperature at the inlet position is kept constant, the temperature at the outlet depends on the residence time of metal in the roll gap. A mean time necessary for the metal to move from $x=a$ to $x=b$ in the roll gap can be given by eq. (2).

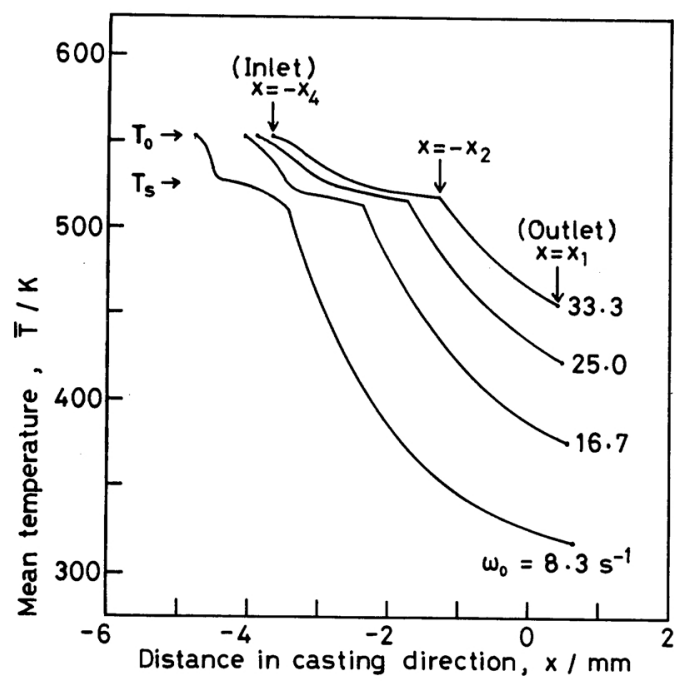

Fig. 6 Distributions of mean temperature in casting direction. $\left(2 H_{00}=50 \mu \mathrm{m}, Q^{\prime}=2.0 \mathrm{~g} / \mathrm{s}\right)$

$$
\bar{t}(a, b)=\frac{2}{q}\left[\left(H_{0}+R\right)(b-a)-\frac{1}{2}\left\{b \sqrt{R^{2}-b^{2}}-a \sqrt{R^{2}-a^{2}}+R^{2}\left(\arcsin \frac{b}{R}-\arcsin \frac{a}{R}\right)\right\}\right]
$$

where $H_{0}$ is the roll gap during rolling and $R$ the roll radius. The residence time from the inlet to the outlet calculated by eq. (2) for the conditions in Fig. 6 is 13.0, 5.0, 2.8 and $2.1 \mathrm{~ms}$, respectively, when the roll rotation speed is $8.3,16.7,25.0$ and $33.3 \cdot \mathrm{s}^{-1}$. The residence time of metal suddenly gets shorter as the roll speed increases.

The cooling rate of the metal in the roll gap can be calculated from the temperature change along the stream lines shown in Figs. 4 and 5 . However, the cooling rate changes not only in the casting direction but also in the thickness direction. Thus, for convenience' sake, a cooling rate defined by eq. (3) was calculated to examine effects of the process parameter on it.

$$
R_{\mathrm{c}}=|\mathrm{d} \bar{T} / \mathrm{d} t|=\bar{v}_{\mathrm{x}} \cdot|\mathrm{d} \bar{T} / \mathrm{d} x|
$$

where $t$ is time $\left(=x / \bar{v}_{\mathrm{x}}\right), \bar{v}_{\mathrm{x}}$ the cross-sectional mean velocity in the casting direction and $\bar{T}$ the cross-sectional mean temperature.

Figure 7 shows the effect of roll rotation speed on the mean cooling rate of metal. In the figure, $\bar{R}_{\mathrm{c}, l}$ denotes the cooling rate averaged over the melt region from the inlet to a position, where the melt commences to solidify, and $\bar{R}_{\mathrm{c}, \mathrm{s}}$ that averaged over the solid region from

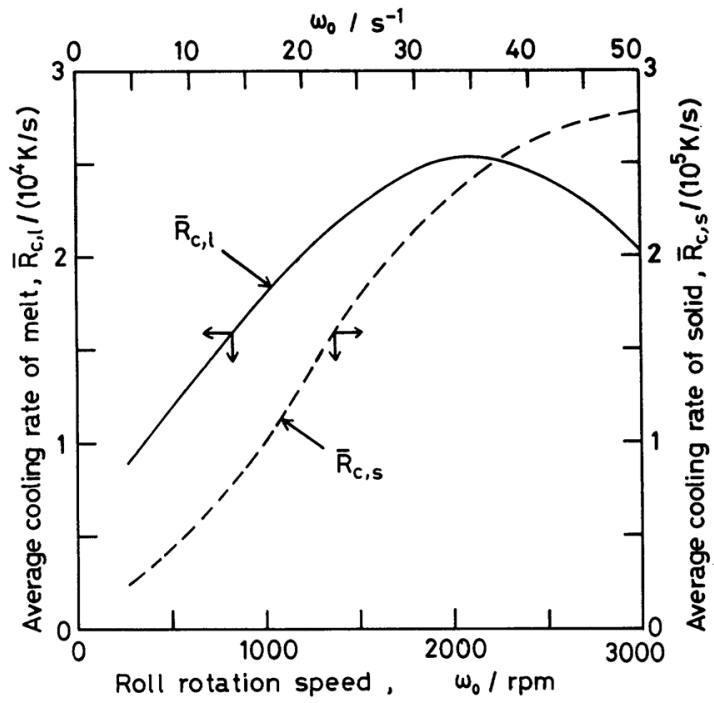

Fig. 7 Effects of roll rotation speed on average cooling rates in melt and solid regions. $\left(2 H_{00}=50 \mu \mathrm{m}\right.$, $Q^{\prime}=2.0 \mathrm{~g} / \mathrm{s}$ )

the end point of solidification to a position, where the cross-sectional mean temperature is lower by $20 \mathrm{~K}$ than the solidification temperature $\left(\bar{T}=T_{\mathrm{s}}-20\right)$. It is seen in Fig. 7 that $\bar{R}_{\mathrm{c}, \mathrm{s}}$ monotonously increases with increasing roll rotation speed, while $\bar{R}_{\mathrm{c}, l}$ has the maximum at a 
roll speed $\left(\approx 35 \mathrm{~s}^{-1}\right)$, which corresponds to the experimental results in Fig. 2. The peak of $\bar{R}_{\mathrm{c}, l}$ results from the increase in $\bar{v}_{\mathrm{x}}$ and the decrease in $\mathrm{d} \bar{T} / \mathrm{d} x$ of eq. (3) with increasing roll rotation speed. It should be stressed that $\bar{R}_{\mathrm{c}, \mathrm{s}}$ is roughly one order higher than $\bar{R}_{\mathrm{c}, l}$.

Figure 8 shows the effect of initial roll gap on the cooling rate of ribbon. With increasing initial roll gap, the mean cooling rate in the solid region $\left(\bar{R}_{\mathrm{c}, \mathrm{s}}\right)$ increases and that in the melt region $\left(\bar{R}_{\mathbf{c}, l}\right)$ decreases. The decrease in $\bar{R}_{\mathbf{c}, l}$ is qualitatively consistent with that obtained from the solidification structure of ribbon in Fig. 3. Hence, the observed dependence of the ribbon structure on the cooling rate in Figs. 2 and 3 can be explained using the calculated mean cooling rate in the melt region between rolls. On the other hand, although the increase in $\bar{R}_{\mathrm{c}, \mathrm{s}}$ shown in Figs. 7 and 8 corresponds to the decrease in metal thickness at the end point of solidification, which is caused by the downward movement of the end point with the increases in roll rotation speed and in initial roll gap, the mean cooling rate in the solid region $\left(\bar{R}_{\mathrm{c}, \mathrm{s}}\right)$ is not useful for predicting the ribbon structure.

Figure 9 shows the effect of melt flow rate on the cooling rate of ribbon. Both the mean cooling rates $\left(\bar{R}_{\mathrm{c}, l}\right.$ and $\left.\bar{R}_{\mathrm{c}, \mathrm{s}}\right)$ slightly decrease with increasing melt flow rate. When the flow rate is increased, the ribbon width increases

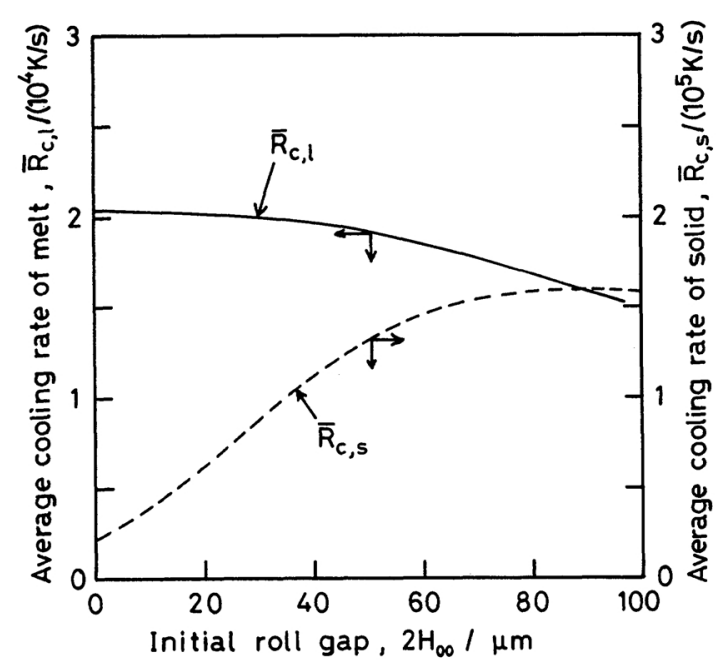

Fig. 8 Effects of initial roll gap on average cooling rates in melt and solid regions. $\left(\omega_{0}=20.8 \mathrm{~s}^{-1}\right.$ $\left.(1250 \mathrm{rpm}), Q^{\prime}=2.7 \mathrm{~g} / \mathrm{s}\right)$

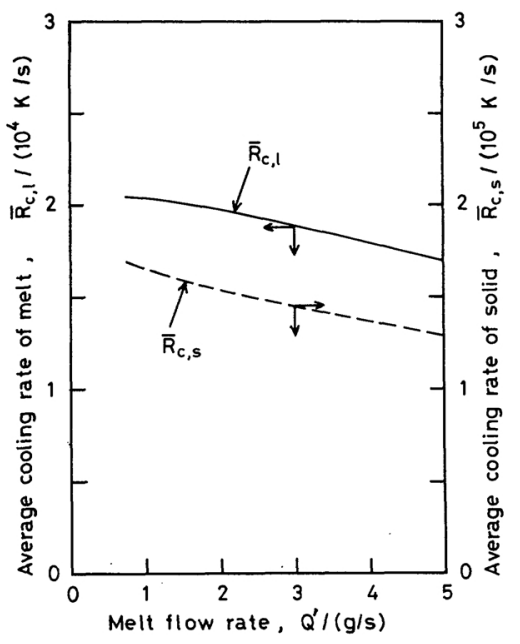

Fig. 9 Effects of melt flow rate on average cooling rates in melt and solid regions. $\left(\omega_{0}=20.8 \mathrm{~s}^{-1}\right.$ (1250 $\mathrm{rpm}), 2 H_{00}=55 \mu \mathrm{m}$ )

linearly, while the changes in such process variables as the inlet and outlet positions, the end point of solidification, the ribbon thickness, the mean velocity of metal $\left(\bar{v}_{\mathrm{x}}\right)$ and the gradient of the mean temperature $(\mathrm{d} \bar{T} / \mathrm{d} x)$ are not significant. Consequently, the changes in $\bar{R}_{\mathrm{c}, \mathrm{s}}$ and $\bar{R}_{\mathrm{c}, l}$ are small for the conditions in Fig. 9.

\section{Conclusions}

Solidification structure of a $\mathrm{Pb}-\mathrm{Sb}$ eutectic alloy ribbon rapidly solidified by the twin-roll process was examined, and the cooling rate was estimated using a mathematical model to explore cooling characteristics of the process. Results obtained are as follows:

(1) In a preliminary rapid quenching from the melt, the white Sb crystals in the eutectic structure become globular and the mean size decreases, as the cooling rate of melt is higher.

(2) Regarding the structure of the ribbon produced by the twin-roll process, the mean size and the area ratio of the white $\mathrm{Sb}$ phase have the minima at a roll rotation speed and decrease with decreasing initial roll gap. The dependence of the structure on the melt flow rate has not been remarkably detected under the experimental conditions adopted here. An effect of the rolling deformation of ribbon just 
after the solidification has been considered to appear on the structure more easily with decreasing roll rotation speed and initial roll gap, because the reduction ratio in the thickness of solidified metal increases.

(3) Using a mathematical model, a mean cooling rate in the melt region between rolls has been estimated to increase with decreasing initial roll gap and to have the maximum at a roll rotation speed. These estimated results qualitatively agree with those detected by examining the solidification structure.

\section{REFERENCES}

(1) K. Miyazawa, T. Choh and M. Inouye: Trans. JIM, 24 (1983), in press.

(2) I. Müller: Metall., 33 (1979), 929.

(3) G. R. Kotler, K. W. Casey and G. S. Cole: Met.
Trans. 3 (1972), 723.

(4) J. A. Spittle and D. M. Lloyd: Solidification and Castings of Metals, The Metals Society, London, (1979), p. 15.

(5) H. Bode und K. Löhberg: Z. Metallk., 70 (1979), 445.

(6) T. W. Clyne and A. Garcia: J. Mater. Sci., 16 (1981), 1643.

(7) K. Inomata, S. Shimanuki and M. Hasegawa: Japan. J. Appl. Phys., 19 (1980), L625.

(8) K. Miyazawa and J. Szekely: Met. Trans. 12A (1981), 1047.

(9) M. Hansen: Constitution of Binary Alloys, 2nd Ed., McGraw-Hill, New York, (1958), p. 1101.

(10) W. A. Tiller: Liquid Metals and Solidification, ASM, Cleveland, Ohio, (1958), p. 276.

(11) W. M. Rumball and V. Kondic: The Solidification of Metals, ISI, London, (1967), p. 149.

(12) C. B.-Gautier, B. C. Giessen and N. J. Grant: J. Chem. Phys., 48 (1968), 1905. 